\title{
The Modulation of Synaptic Transmission by the Glial Purinergic System
}

\author{
Kazuhide Inoue $^{*}, 1$, Fusao Kato ${ }^{2}$ and Makoto Tsuda ${ }^{1}$ \\ ${ }^{I}$ Department of Molecular and System Pharmacology, Graduate School of Pharmaceutical Sciences, Kyushu University, \\ 3-1-1 Maidashi, Higashi, Fukuoka 812-8582, Japan \\ ${ }^{2}$ Laboratory of Neurophysiology, Department of Neuroscience, Jikei University School of Medicine, 3-25-8 Nishishin- \\ bashi, Minato, Tokyo 105-8461, Japan
}

\begin{abstract}
Accumulating evidence indicates that bioactive substances produced by glia play an important role in the modulation of synaptic transmission. Astrocytes and microglia express many types of P2 purinoceptors and the stimulation of these receptors causes the release of bioactive substances, termed "gliotransmitters", such as ATP, glutamate and cytokines. Gliotransmitters are able to modulate synaptic transmission. In this article, the $\mathrm{P} 2 \mathrm{X}_{4} \mathrm{R}$ and $\mathrm{P} 2 \mathrm{Y}_{12} \mathrm{R}$ systems of microglia, which modulate the synaptic transmission between dorsal root ganglion neurons and dorsal horn neurons, are described. In addition, the role of the astrocyte purinergic system in synaptic transmission is discussed. The modulation of synaptic transmission by glial purinergic systems is a novel perspective on the regulation of brain and nerve function and is a new target for the development of medicines.
\end{abstract}

Keywords: ATP receptors, microglia, astrocyte, synaptic transmission.

\section{INTRODUCTION}

In 1972, Burnstock proposed new a role for nucleotides; that of neurotransmission [1]. Recently, numerous subtypes of ATP and adenosine receptor have been cloned, which has led to the acceptance of the "purinergic nervous system". Now purinergic receptors are divided into two big families, P1 (receptors for adenosine and AMP) and P2 (receptors for nucleotides). Four subtypes of P1 receptors have been cloned, namely, $\mathrm{A}_{1}, \mathrm{~A}_{2 \mathrm{~A}}, \mathrm{~A}_{2 \mathrm{~B}}$, and $\mathrm{A}_{3}$. $\mathrm{P} 2$ purinoceptors are divided into two families, ionotropic receptors $(\mathrm{P} 2 \mathrm{X})$ and metabotropic receptors (P2Y) [2]. P2X receptors (7 types; $\mathrm{P} 2 \mathrm{X}_{1}-\mathrm{P} 2 \mathrm{X}_{7}$ ) contain intrinsic pores that allow the flow of ions. P2X receptors switch conformation from closed to open on binding ATP. P2Y receptors (8 types; $\mathrm{P}_{1,2,4,6,11 \text {, }}$ 12,13 and 14 ) are activated by purine or pyrimidine nucleotides or by sugar-nucleotides (which is subtype-dependent) and couple to intracellular second-messenger systems through heterotrimeric G-proteins [3-5].

Nucleotides are released or leaked from non-excitable cells, as well as from neurons and play a role in cell-to-cell communication in physiological and pathophysiological conditions $[2,6]$. One of the most interesting non-excitable cells is the glial cell, which makes up over $70 \%$ of the total cell population in the central nervous system $(\mathrm{CNS})$ and is classified into astrocytes, oligodendrocytes and microglia. Astrocytes express several types of P2 purinoceptors and release bioactive substances, including ATP in response to various stimuli or even spontaneously, and communicate with neurons and microglia. Microglia also express some types of $\mathrm{P} 2$ purinoceptors and are known as resident macro-

*Address correspondence to this author at the Department of Molecular and System Pharmacology, Graduate School of Pharmaceutical Sciences, Kyushu University, Maidashi 3-1-1, Higashi-ku, Fukuoka 812-8582, Japan; Tel/Fax=+81-92-642-4729; E-mail: inoue @phar.kyushu-u.ac.jp phages in the CNS, accounting for 5-10\% of the total population of glia [7, 8]. Recent evidence has suggested that glial cells activated by the result of neuron-glia and glia-glia interactions through purinergic receptors release gliotransmitters (ATP, glutamate, cytokines, etc.), thereby affecting synaptic transmission. In this article, we describe the modulation of synaptic transmission by the glial purinergic system.

\section{MICROGLIA}

\subsection{Microglial Activation}

Microglia express functionally active $\mathrm{P} 2$ receptors [9]. In the adult, microglia are ubiquitously distributed throughout the CNS and represent a morphologically unique type of cell which, under normal conditions, have a small soma bearing thin and branched processes. Such microglia were considered as 'resting', but recent studies investigating a transgenic mouse line that expressed green fluorescent protein in microglia using two-photon microscopy to image the behavior of these cells have revealed that microglial processes are highly dynamic in the brain $[10,11]$. The processes of microglia rapidly move toward the site of injury, an effect that is mimicked by local injection of ATP and can be inhibited either by the ATP-hydrolyzing enzyme apyrase or by blockers of P2YRs [10]. Furthermore, Haynes et al. (2006) have shown that microglia in $\mathrm{P}_{2} \mathrm{Y}_{12} \mathrm{R}$-deficient mice exhibit normal basal motility but diminished directional branch extension toward nucleotides or sites of cortical damage in vivo [12]. Thus, microglia appear to act as sensors using the nucleotide/ $\mathrm{P} 2 \mathrm{Y}_{12} \mathrm{R}$ system.

When neurons are injured or over-stimulated, microglia undergo a stereotypical program of changes in morphology, gene expression, function and number to become activated microglia $[13,14]$. Activated microglia migrate to the site of injury, release gliotransmitters, and engulf and phagocytose damaged cells or debris. These actions of microglia will af- 
fect synaptic transmission. For the activation of microglial motility, extracellular nucleotides have a central role. Extracellular ATP functions as a chemoattractant. Microglial chemotaxis towards ATP, via $\mathrm{P}_{2} \mathrm{Y}_{12}$ receptors, was originally observed by Honda et al. (2001) [15] and has recently been confirmed in vivo in $\mathrm{P}_{2} \mathrm{Y}_{12}$ receptor knock-out animals [12].

\subsection{Microglial $\mathbf{P} 2 \mathrm{X}_{4} \mathrm{R}$ Modulation of Synaptic Transmis- sion in Primary Afferent Nerves and Dorsal Horn Neu- rons}

There is a type of chronic pain that does not abate even though tissue damage has healed. This type pain is called 'neuropathic pain' and it typically develops when peripheral nerves are damaged, such as during surgery, bone compression in cancer, diabetes or infection. In addition to spontaneous pain and hyperalgesia (the increased pain perception of noxious stimuli), a troublesome symptom is known as tactile allodynia, a phenomenon of pain sensation evoked by innocuous stimuli. In normal conditions, innocuous stimuli cause touch sensation, mediated through the dorsal root ganglia (DRG) neuron $A \beta$, which does not conduct pain sensation. Therefore, tactile allodynia is thought to be a shift in the modality of sensation. The mechanism of neuropathic pain is still not fully understood. A variety of animal models for studying neuropathic pain have been developed, and in all models examined, activation of microglia in the dorsal horn is observed after nerve injury [13, 16-25]. Peripheral nerve damage leads to a dramatic change in the microglia within the spinal dorsal horn; these cells become activated through a step-by-step process [13]. Within the first $24 \mathrm{hrs}$ after peripheral nerve injury, the first signs of microglial activation can already be observed: the small soma become hypertrophic and the long and thin processes withdraw [16]. This is followed by a burst of proliferation, with a peak around 2 3 days after nerve injury [21, 22, 26-28]. Also, activated microglia upregulate the expression of complement receptor 3 leading to enhanced OX-42 labeling [16-19, 29], with peak enhancement observed around 14 days after injury $[17,20]$.

An important question is how microglia in the spinal cord become activated when the nerve injury may occur at a very great distance from the spinal cord. The signal(s) of injury in sensory or mixed nerves remains obscure but candidate signaling molecules involved in microglial activation are growth factors, cytokines, chemokines and neurotransmitters [13]. A potential candidate is monocyte chemoattractant protein-1 (MCP-1) whose expression is markedly increased in DRG neurons after nerve injury [20, 30, 31]. The timecourse of MCP-1 upregulation in DRG neurons is similar to that of microglial activation [20]. Recently, it was found that mice lacking either toll-like receptor 4 (TLR4) or 2 (TLR2), which are type I transmembrane signaling proteins that recognize pathogen-associated molecular patterns, showed impaired microglia activation in the dorsal horn after nerve injury $[32,33]$. Thus, TLRs also appear to play an important role in nerve injury-induced microglia activation in the spinal cord. However, the identity of endogenous ligands for these receptors remains to be determined. A recent study has indicated that interferon- $\gamma(\mathrm{IFN}-\gamma \mathrm{R})$ levels are increased in the spinal cord after nerve injury, leading to speculation that it has a role in neuropathic pain [32]. However, there was no direct evidence indicating that IFN- $\gamma$ signaling contributes to microglial activation in the dorsal horn and to tactile allodynia under neuropathic pain conditions. More recently, Tsuda et al. reported that in naive animals, spinal microglia express a receptor for IFN- $\gamma \mathrm{R}$ in a cell-type specific manner and that stimulating this receptor converts microglia into activated cells and produces a long-lasting tactile allodynia [34]. Conversely, ablating IFN- $\gamma \mathrm{R}$ severely impairs nerve injury-evoked microglia activation and tactile allodynia without affecting microglia in the contralateral dorsal horn or basal pain sensitivity. These results imply that IFN- $\gamma \mathrm{R}$ is a key element in the molecular machinery through which 'resting' spinal microglia transform into an activated state and, thereby, drive neuropathic pain.

There is abundant evidence demonstrating activation of spinal microglia in the neuropathic pain state, but until recently it remained an open question as to whether spinal microglia play a causal role in neuropathic pain. Tsuda et al. (2003) directly implicated activated microglia in the pathogenesis of neuropathic pain by determining the role of the purinoceptor $\mathrm{P} 2 \mathrm{X}_{4} \mathrm{R}$. A clue to identifying $\mathrm{P} 2 \mathrm{X}_{4} \mathrm{Rs}$ in the spinal cord as being required for neuropathic pain first came from pharmacological investigation of pain behavior after nerve injury using the $\mathrm{P} 2 \mathrm{X}$ receptor antagonists TNP-ATP and PPADS [22]. The marked tactile allodynia after an injury to the spinal nerve was found to be reversed by acute intrathecal administration of TNP-ATP but was unaffected by the administration of PPADS. From the pharmacological profiles of TNP-ATP and PPADS, it was inferred that the tactile allodynia depends upon $\mathrm{P}_{2} \mathrm{X}_{4} \mathrm{Rs}$ in the spinal cord. Expression of $\mathrm{P} 2 \mathrm{X}_{4} \mathrm{R}$ protein progressively increased in the days following nerve injury, the time-course of which parallels that of the development of tactile allodynia. Immunohistochemical analyses showed that many small cells in the dorsal horn of the nerve-injured side were positive for $\mathrm{P} 2 \mathrm{X}_{4} \mathrm{R}$ protein, and these cells were identified as microglia. The cells expressing $\mathrm{P} 2 \mathrm{X}_{4} \mathrm{R}$ in the nerve-injured side of the dorsal horn showed high levels of OX-42 and morphological hypertrophy, which are characteristic markers of activated microglia. Moreover, it was found that reducing the upregulation of $\mathrm{P} 2 \mathrm{X}_{4} \mathrm{R}$ protein in spinal microglia using $\mathrm{P} 2 \mathrm{X}_{4} \mathrm{R}$ antisense oligodeoxynucleotides prevented the development of nerve injury-induced tactile allodynia. Finally, Tsuda et al. reported that in mice with a disrupted $p 2 r \times 4$ gene $\left(p 2 r \times 4^{-/}\right.$mice), tactile allodynia caused by an injury to the spinal nerve was markedly blunted [22, 35, 36]. Together, these observations implied that activation of $\mathrm{P} 2 \mathrm{X}_{4} \mathrm{Rs}$ in spinal microglia is necessary for neuropathic pain. $\mathrm{P} 2 \mathrm{X}_{4} \mathrm{R}$ activation in microglia was shown to be sufficient for the development of allodynia by intrathecal administration of activated, cultured microglia in which these receptors had been stimulated by ATP in vitro [22]. In otherwise naïve animals, allodynia develops progressively over the 3-5 hours following the administration of the $\mathrm{P} 2 \mathrm{X}_{4} \mathrm{R}$-stimulated microglia. Moreover, in rats in which tactile allodynia was caused by ATP-stimulated microglia this allodynia was reversed by administering TNP-ATP [22]. Thus, the allodynia caused by ATP-stimulated microglia is pharmacologically similar to that caused by peripheral nerve injury. Together, these findings indicate that $P 2 X_{4} R$ stimulation of microglia is not only necessary for tactile allodynia but also is sufficient to cause the allodynia. 
Enhanced synaptic transmission and firing discharge of neurons in the dorsal horn pain-processing network following nerve injury is crucial for neuropathic pain syndromes $[37,38]$. The first evidence that microglia may participate in the hyperexcitability of dorsal horn neurons was revealed by Coull et al. (2005). They used spinal cord slices taken from rats displaying allodynia following intrathecal administration of $\mathrm{P} 2 \mathrm{X}_{4} \mathrm{R}$-stimulated microglia and found that ATPstimulated microglia positively shifted the anion reversal potential $\left(\mathrm{E}_{\text {anion }}\right)$ in spinal lamina I dorsal horn neurons [39]. In normal conditions, a touch stimulation evokes an impulse in DRG $A \beta$ neurons, which partially innervate inhibitory interneurons resulting in the release of the neurotransmitter, GABA. GABA opens chloride channels and normally causes hyperpolarization of dorsal horn neurons to diminish the pain sensation. In this abnormal condition, GABA released by touch stimulation causes depolarization rather than hyperpolarization in DH neurons, thereby evoking pain sensation [39]. Moreover, TNP-ATP which can reverse nerve injuryinduced allodynia [22] acutely reverses the depolarizing shift in $E_{\text {anion }}$ in lamina $I$ neurons after peripheral nerve injury [39]. Together with the findings that the depolarizing shift in $\mathrm{E}_{\text {anion }}$ and the excitatory response to GABA are key events in dorsal horn neurons in neuropathic pain after nerve injury [40], these results imply that spinal microglia stimulated by $\mathrm{P} 2 \mathrm{X}_{4} \mathrm{R}$ cause neuropathic pain through a rise in intracellular $\mathrm{Cl}^{-}$in spinal lamina I DH neurons.

The next question is, "what are the underlying mechanisms for the microglial affect on the anion balance in lamina I DH neurons'? Coull et al. (2005) determined the role of brain-derived neurotrophic factor (BDNF) as a signaling factor between microglia and dorsal horn lamina I neurons. It was found that intrathecal application of BDNF mimicked tactile allodynia and the depolarizing shift in $\mathrm{E}_{\text {anion }}$ in lamina I neurons following peripheral nerve injury or intrathecal administration of $\mathrm{P} 2 \mathrm{X}_{4} \mathrm{R}$-stimulated microglia. Furthermore, interfering with signaling between BDNF and its receptor (TrkB), either by a function-blocking TrkB antibody or by a BDNF-sequestering fusion protein (TrkB-Fc), prevented tactile allodynia caused by peripheral nerve injury or by intrathecal administration of P2X4R-stimulated microglia. Moreover, activation of $\mathrm{P} 2 \mathrm{X}_{4} \mathrm{R}$ on microglial cells caused the release of BDNF [39, 41], an effect that is dependent on activation of p38 [41], a member of the mitogen-activated protein kinase family that is implicated in neuropathic pain $[42,43]$. Interestingly, $\mathrm{P}_{2} \mathrm{X}_{4}$-mediated $\mathrm{BDNF}$ release was abolished by inhibiting SNARE (soluble $N$-ethylmaleimidesensitive factor attachment protein receptor)-mediated exocytosis. Thus, these results indicate that $\mathrm{P} 2 \mathrm{X}_{4}$-stimulated microglial release of BDNF causes a collapse in the transmembrane anion gradient and subsequent neuronal hyperexcitability in lamina I neurons (Fig. 1). The $\mathrm{GABA}_{\mathrm{A}} \mathrm{R}$-mediated depolarization might also produce an excitation through voltage-sensitive $\mathrm{Ca}^{2+}$ channels and NMDA receptors. There is also evidence that several proinflammatory cytokines which are known to be released from microglia $[9,44]$ modulate excitatory synaptic transmission. Interleukin- $1 \beta$ was reported to enhance the NMDA receptor-mediated $\mathrm{Ca}^{2+}$ response [45], while long-term treatment with interferon- $\gamma$ produced an increase in neuronal excitability in dorsal horn neurons [46]. Thus, the net enhanced transmission in the dorsal horn pain network by these factors might be responsible for nerve injury-induced neuropathic pain (Fig. 1).

Upregulation of $\mathrm{P} 2 \mathrm{X}_{4} \mathrm{R}$ in microglia is an important process in producing neuropathic pain. Nasu-Tada et al. (2006) reported the role of fibronectin, an extracellular matrix protein, as a potential candidate for inducing $\mathrm{P} 2 \mathrm{X}_{4} \mathrm{R}$ upregulation in microglia. It was found that microglia cultured on fibronectin-coated dishes showed a marked increase in $\mathrm{P} 2 \mathrm{X}_{4} \mathrm{R}$ expression both at the mRNA and protein levels [47]. This upregulation of $\mathrm{P} 2 \mathrm{X}_{4} \mathrm{R}$ protein by fibronectin might be functional as the $\mathrm{P} 2 \mathrm{X}_{4} \mathrm{R}$-mediated $\mathrm{Ca}^{2+}$ response was enhanced in fibronectin-treated microglia. Tsuda et al. found that in fibronectin-stimulated microglia, activation of phosphatidylinositol 3-kinase (PI3K)-Akt and mitogenactivated protein kinase kinase (MAPK kinase, MEK)extracellular signal-regulated kinase (ERK) signaling cascades occurred divergently downstream of the Src-family kinase (SFK), Lyn, in microglia [48]. Pharmacological interference of PI3K-Akt signaling inhibited fibronectin-induced $\mathrm{P} 2 \mathrm{X}_{4} \mathrm{R}$ gene expression. Activation of PI3K-Akt signaling resulted in a decrease in the protein level of the transcription factor p53 via mouse double minute 2 (MDM2), an effect that was prevented by MG-132, an inhibitor of the proteasome. In microglia pretreated with MG-132, fibronectin failed to upregulate $\mathrm{P} 2 \mathrm{X}_{4} \mathrm{R}$ expression. Conversely, an inhibitor of p53 caused increased expression of $\mathrm{P} 2 \mathrm{X}_{4} \mathrm{R}$, implying a negative regulatory role of $\mathrm{p} 53$. On the other hand, inhibiting MEK-ERK signaling activated by fibronectin suppressed an increase in $\mathrm{P} 2 \mathrm{X}_{4} \mathrm{R}$ protein levels but, interestingly, did not affect the level of $\mathrm{P} 2 \mathrm{X}_{4} \mathrm{R}$ mRNA. Fibronectin stimulation resulted in the activation of the translational factor eIF4E via MAPK-interacting protein kinase-1 (MNK1) in a MEK-ERK signaling-dependent manner, and an MNK1 inhibitor attenuated the increase in $\mathrm{P} 2 \mathrm{X}_{4} \mathrm{R}$ protein. Together, these results suggest that the PI3K-Akt and MEK-ERK signaling cascades have distinct roles in the upregulation of $\mathrm{P} 2 \mathrm{X}_{4} \mathrm{R}$ expression in microglia at transcriptional and posttranscriptional levels, respectively [48]. Tsuda et al. also found that IFN- $\gamma$-stimulated spinal microglia showed upregulation of Lyn (a tyrosine kinase) and the purinergic $\mathrm{P} 2 \mathrm{X}_{4}$ receptor, which are crucial events for the generation of neuropathic pain. Genetic approaches also provide evidence linking these events to IFN- $\gamma \mathrm{R}$-dependent microglial and behavioral alterations $[34,49]$. It was also reported that activating both TLRs and NOD2 in cultured microglia increased expression of $\mathrm{P} 2 \mathrm{X}_{4} \mathrm{R}$ at the mRNA level [50], thus implying an involvement of these receptors in the regulation of $\mathrm{P} 2 \mathrm{X}_{4} \mathrm{R}$. More research is required to reveal the complete mechanism underlying over-expression of $\mathrm{P} 2 \mathrm{X}_{4} \mathrm{R}$ in activated microglia after nerve injury.

\section{ASTROCYTES}

\subsection{ATP Receptors in Cultured Astrocytes}

Since the first reports of elevations in $\left[\mathrm{Ca}^{2+}\right] \mathrm{i}$ in cultured astrocytes in response to neurotransmitters [51, 52] it has become apparent that many types of neurotransmitter stimulate $\mathrm{Ca}^{2+}$ elevations in glial cells by activating specific receptors. These receptors include metabotropic glutamate receptors, dopamine receptors, noradrenaline receptors, serotonin receptors and purinergic receptors [53], whose activation results in elevations in $\left[\mathrm{Ca}^{2+}\right] \mathrm{i}$ in astrocytes. Glutamate can 


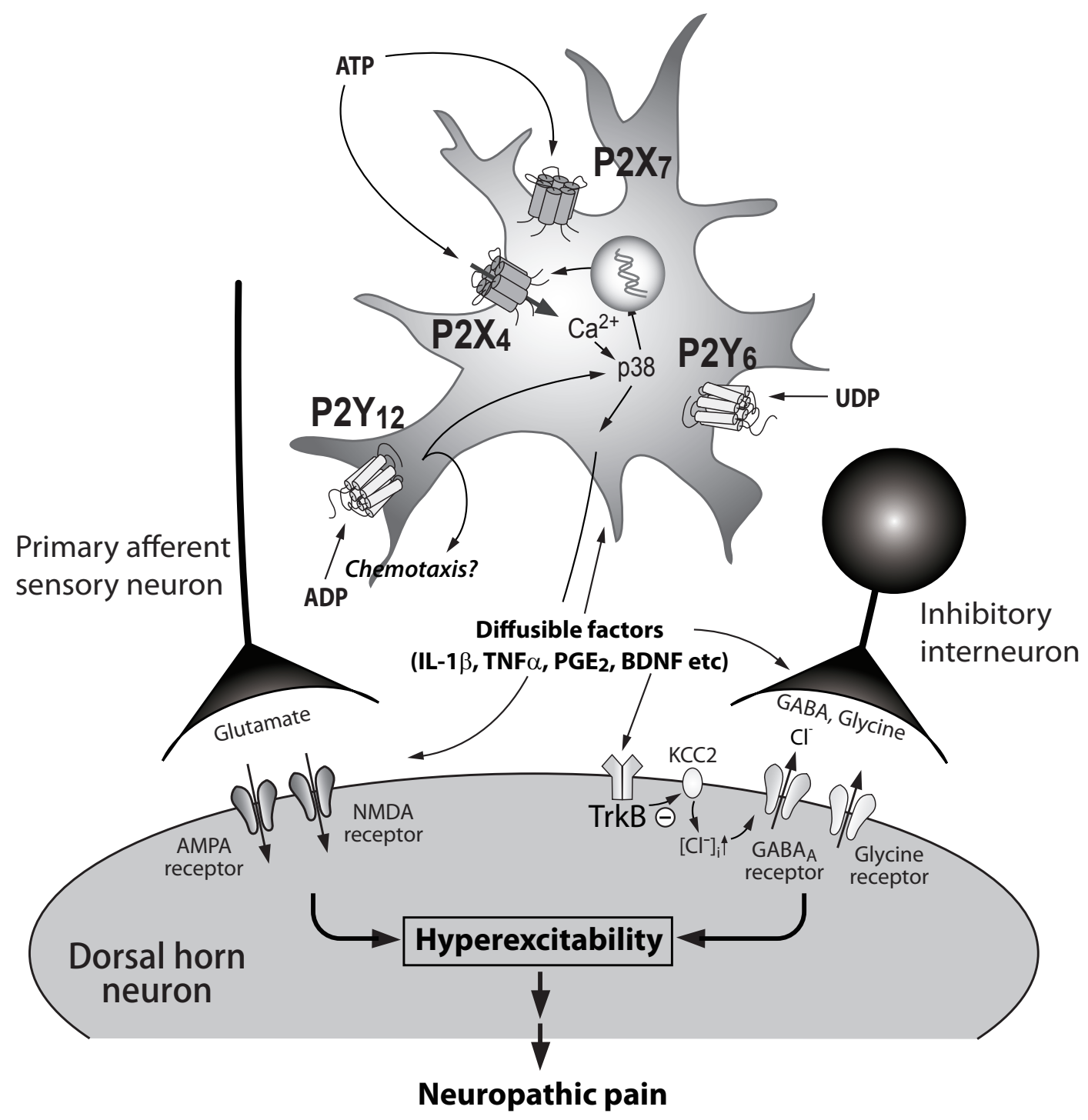

Fig. (1). Schematic illustration of microglial modulation of synaptic transmission in primary afferent nerves and dorsal horn neurons. After peripheral nerve injury, microglia in the spinal cord ipsilateral to the nerve injury become transformed to the activated phenotype (hypertrophy, proliferation, and the expression of cell-surface molecules). Activated microglia after nerve injury increase the expression of $\mathrm{P} 2 \mathrm{X}_{4} \mathrm{R}$. The $\mathrm{P} 2 \mathrm{X}_{4} \mathrm{R}$ are activated by ATP resulting in the release of bioactive diffusible factors such as BDNF and other proinflammatory factors (cytokines and chemokines). BDNF causes a collapse of the transmembrane anion gradient in dorsal horn lamina I neurons presumably through the downregulation of KCC2, which in turn renders GABA and glycine affects depolarizing, rather than hyperpolarizing, in these neurons. Microglial factors (cytokines, $\mathrm{PGE}_{2}$, etc) may also interact with excitatory synapses of neighboring dorsal horn neurons and enhance the excitability in dorsal horn neurons. The net hyperexcitability in the dorsal horn network by these factors from activated microglia may be responsible for abnormal pain signaling.

elicit $\left[\mathrm{Ca}^{2+}\right]$ i elevation not only in individual cells but also in intercellular waves $\left[\mathrm{Ca}^{2+}\right] \mathrm{i}$ that are propagated from single cells to multiple neighboring cells [52]. Neuronal activity can directly initiate such a $\mathrm{Ca}^{2+}$ wave in astrocytes [54]. Other stimuli, such as local mechanical or electrical stimulation, were subsequently observed to initiate similar intercellular $\mathrm{Ca}^{2+}$ signaling in astrocytes. $\mathrm{Ca}^{2+}$ waves were thought to propagate via gap junctions [55-57], through which the internal messenger inositol 1,4,5-triphosphate $\left(\mathrm{IP}_{3}\right)$ can diffuse to mobilize $\mathrm{Ca}^{2+}$ release [57]. Recent experiments in culture showed that $\mathrm{Ca}^{2+}$ waves can be propagated between astrocytes, even when the cells do not contact each other directly, and the extent and direction of the $\mathrm{Ca}^{2+}$ wave propagation are significantly influenced by movement of the extracellular medium [58]. Recent reports suggest that substances released from astrocytes can activate receptor systems on astrocytes, evoking the release of gliotransmitters. Importantly, it was found that extracellular ATP is the major messenger for this event. ATP is released from astrocytes during $\mathrm{Ca}^{2+}$ wave propagation [58], and the propagation can be reduced or abolished by a purinergic antagonist [58] [5962] or by the ATP degrading enzyme apyrase [58, 62]. In addition, it was demonstrated by a method for the visualization of ATP release that the velocity of ATP release correlates well with that of the $\mathrm{Ca}^{2+}$ wave in astrocytes [62]. These findings suggest that the extracellular molecule ATP 
could be a primary signal for the $\mathrm{Ca}^{2+}$ wave propagation, and highlights the importance of ATP in cross-talk among astrocytes and even with other cell types in the CNS (Fig. 2).

Astrocytic ATP also mediates presynaptic inhibition in cultured hippocampal neurons [62, 63]. Cultured hippocampal neurons exhibit synchronous spontaneous $\mathrm{Ca}^{2+}$ oscillation, which is extracellular $\mathrm{Ca}^{2+}$-dependent, tetrodotoxinsensitive and inhibited by inhibitors of ionotropic glutamate receptors, suggesting that the neuronal $\mathrm{Ca}^{2+}$ oscillation is mediated by glutamatergic synaptic transmission [62, 64, 65]. Endogenous ATP released from astrocytes dynamically down-regulates spontaneous neuronal $\mathrm{Ca}^{2+}$ oscillations [62] and EPSCs in the hippocampal culture [63] by inhibiting presynaptic functions of glutamatergic neurons.

ATP differs from glutamate as a signaling molecule between astrocytes and neurons in that it inhibits rather than potentiates synaptic transmission. It is hypothesized that the opposing actions of glutamate and ATP released from astrocytes represent a means by which astrocytes can dynamically modulate neuronal activity by releasing distinct transmitters which can either excite or inhibit synaptic transmission. In addition to mediating inhibitory rather than excitatory effects on synaptic transmission, ATP-mediated astrocyte-to-neuron signaling further differs from glutamate-dependent signaling mechanisms by the fact that it occurs in a tonic fashion [62] $[63,66]$. When the ATP-degrading enzyme apyrase was applied, a potentiation of spontaneous neuronal $\mathrm{Ca}^{2+}$ oscillations or EPSCs was induced in the absence of any astrocytic stimulation. This means the presence of a constitutive ATPdependent inhibition of synaptic transmission. Furthermore, spontaneous astrocytic $\mathrm{Ca}^{2+}$ responses occur in both purified astrocyte cultures and in mixed cultures of astrocytes and neurons. The spontaneous $\mathrm{Ca}^{2+}$ signals in astrocytes were inhibited by apyrase but persisted in the presence of TTX. Therefore, astrocytes constitutively release ATP in the absence of neuronal activity, thereby exerting tonic downregulation of excitatory synaptic transmission [62, 63]. ATP mediates astrocytic $\mathrm{Ca}^{2+}$ waves and can evoke neuronal $\mathrm{Ca}^{2+}$ responses in various parts of the CNS, suggesting that ATP may be a ubiquitous mediator of astrocyte-to-neuron signaling in the modulation of synaptic activity. Such a tonic modulation by astrocytic ATP might be a mechanism by which neurons tune their communications in the CNS.

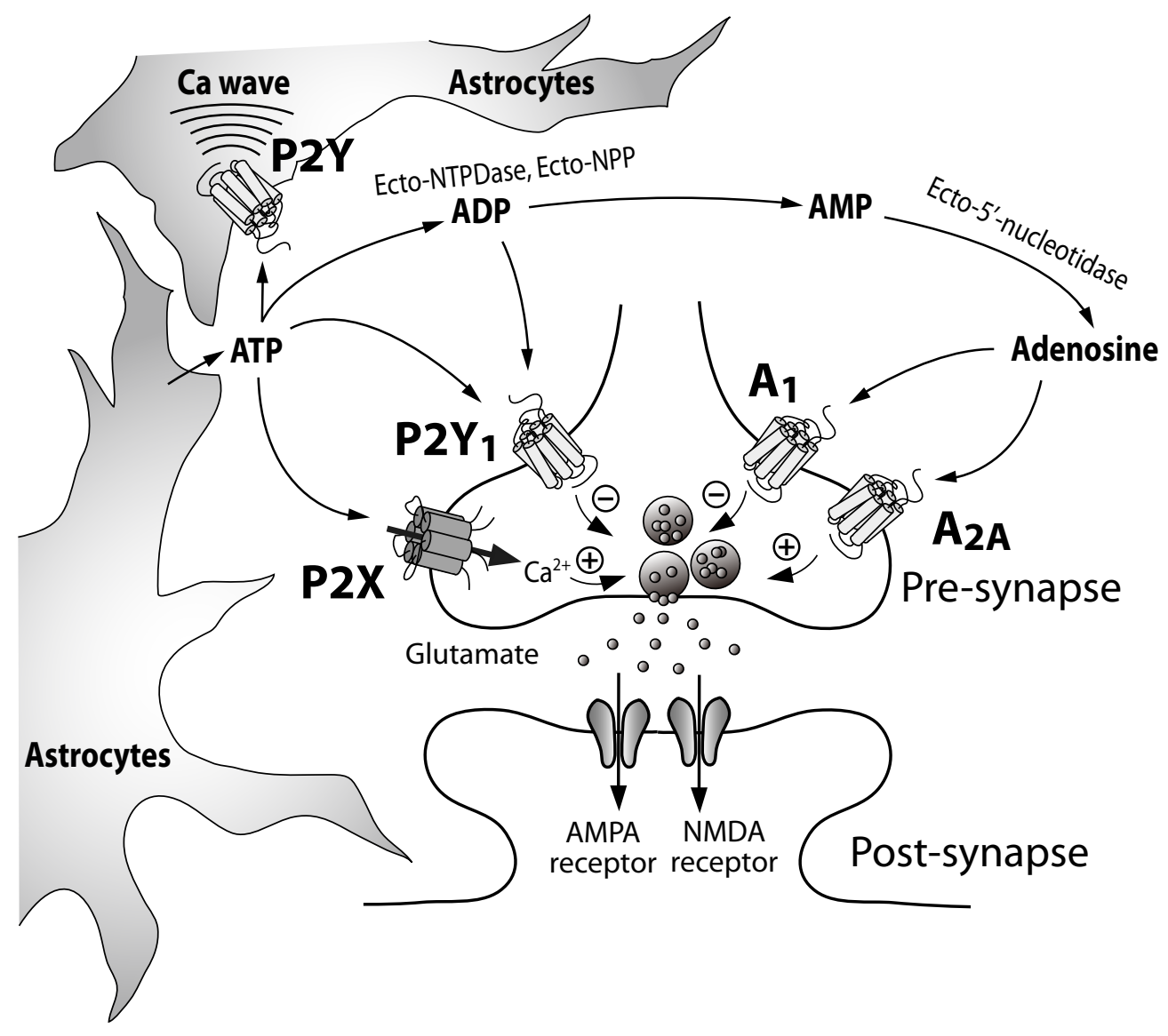

Fig. (2). Schematic illustration of astrocytic modulation of synaptic transmission.

Suppression of glutamatergic transmission by ATP of astrocyte-origin occurs through the activation of presynaptic $\mathrm{P}_{2} \mathrm{Y}_{1}$ receptors in cultured hippocampal neuron-glia co-cultures and the activation of presynaptic $\mathrm{A}_{1}$ receptors in acute slices, due to strong hydrolyzing activity around the synapses in the slices. In contrast, activation of $\mathrm{A}_{2 \mathrm{~A}}$ receptors rather potentiates excitatory transmission. Additionally, in a large variety of central structures, the stimulation of presynaptic P2X receptor by $\alpha, \beta$-methylene ATP facilitate glutamatergic synaptic transmission via direct $\mathrm{Ca}^{2+}$ entry through $\mathrm{P} 2 \mathrm{X}$ receptors. 


\subsection{Adenosine Receptors in the Retina}

ATP molecules are readily cleaved by enzymatic hydrolysis to yield ADP, AMP and adenosine. Adenosine activates $\mathrm{P} 1$ purinergic receptors, for which there are the subtypes $A_{1}, A_{2 A}, A_{2 B}$, and $A_{3}$. Newman reported that astrocytic purinergic signaling in the mammalian retina is related to the suppression of neuronal activity [67]. He also showed that light activation of photoreceptors in the retina leads to $\mathrm{Ca}^{2+}$ signaling in associated Muller glial cells, evoking the release of ATP which causes outward currents in these neurons [68, 69]. Importantly, these inhibitory actions were not mediated directly by ATP, but instead by its metabolite adenosine. Indeed, stimulation of the adenosine $\mathrm{A}_{1}$-receptor induces outward currents, and DPCPX, an $\mathrm{A}_{1}$-receptor antagonist, inhibits the light-induced neuronal suppression that is mediated by glia.

\subsection{The Purinergic System in the Synaptic Glia-Neuron Interaction of In Situ Brain Tissue}

\section{Diverse Effects of Exogenous Purines in Brain Slices}

Exogenous application of various types of P2X, P2Y, $\mathrm{A}_{1}$ and $\mathrm{A}_{2 \mathrm{~A}}$ receptor agonist exerts potent and robust effects on synaptic transmission in brain slices through activating these receptors expressed on the pre- and/or postsynapses. Application of P2X agonists results in a robust inward current, presumably activating the postsynaptic receptors, in the medial habenula [70], cortex [71, 72], locus coeruleus [73], and other structures [74-77] [78]. These postsynaptic P2X receptors can also be activated by electrical stimulation of presynaptic afferent fibers in the slice, suggesting ATP/P2X receptor-mediated fast synaptic transmission [79].

However, compared with the wide distribution of $\mathrm{P} 2 \mathrm{X}$ receptor subunit expression in the brain and also to the $\mathrm{P} 2 \mathrm{X}$ agonist responses reported in isolated or cultured neurons of brain origin, such ATP/P2X receptor-mediated fast transmission has been identified only in limited structures, as listed above. Even in the cases where such transmission occurs, the resulting postsynaptic responses are so small that complete blockade of principal glutamatergic transmission and extremely strong presynaptic stimulation are required to detect them [80, 81]. Rather, in a large variety of central structures, degradation-resistant $\mathrm{P} 2 \mathrm{X}$ receptor agonists such as $\alpha, \beta$ methylene ATP robustly facilitate release of transmitters such as glutamate and GABA, mostly through direct $\mathrm{Ca}^{2+}$ entry through presynaptic $\mathrm{P} 2 \mathrm{X}$ receptors [82-88], suggesting that the major site of action for the extracellular ATP in CNS neurons in situ is in presynaptic structures.

The effects of exogenously applied ATP to neurons in brain slices are more complicated than those in isolated or cultured cells primarily due to the higher-density of enzymes involved in ATP to adenosine conversion [89]. Local application of ATP to the hippocampal pyramidal neurons, for example, evokes robust outward current in a manner sensitive to $A_{1}$ receptor antagonists and inhibitors of ecto-5'nucleotidase [90], suggesting that ATP undergoes a rapid degradation down to adenosine within a few hundred seconds near the synapse sites (Fig. 2). In a similar manner, application of both ATP and adenosine suppresses excitatory transmission in many brain synapses, which are also sensitive to $A_{1}$ antagonists $[85,91-94]$. Involvement of $A_{1}$ recep- tors in this ATP-evoked synaptic suppression in the hippocampus was unequivocally demonstrated by the lack of ATP effect in mice lacking $A_{1}$ receptors [91]. Such effects of ATP resulting from activation of $A_{1}$ receptors are also found in other structures, where ATP plays dual roles, one as a P2 receptor agonist and another as a P1 receptor agonist [85, 92, 95], resulting in complex bi-directional regulation of synaptic transmission (Fig. 2). The situation in the brain slice is more complicated because not only the neurons but also astrocytes express $\mathrm{P} 2 \mathrm{Y}$ and adenosine receptors (but not $\mathrm{P} 2 \mathrm{X}$ receptors [96]), activation of which makes them release many transmitters and mediators including glutamate and ATP, which in turn activates specific neuronal and astrocytic receptors and gives rise to specific responses [97].

Suppression of glutamate release by exogenously applied adenosine $A_{1}$ receptor agonists seems to be a ubiquitous mechanism of synaptic regulation $[93,94]$. In contrast, activation of $\mathrm{A}_{2 \mathrm{~A}}$ receptors with exogenously applied agonists rather potentiates excitatory transmission, a mechanism that might have important implications in corticostriatal regulation[98-100]. Moreover, interactions between presynaptic $A_{1}$ and $\mathrm{A}_{2 \mathrm{~A}}$ receptors [101] and $\mathrm{A}_{2 \mathrm{~A}}$ and dopamine $\mathrm{D}_{2}$ receptors [102] increase the complexity of such purinergic regulation (Fig. 2). This field, which is extremely important for the development of therapeutic treatments against epilepsy [103], Parkinson's disease [98], sleep disorder [104] and agedependent cognitive decline [105, 106], awaits further studies to obtain more complete understanding.

\section{Astrocyte-Neuron Interaction in Synaptic Transmission}

Identification of ATP as a gliotransmitter released from astrocytes [107] helped the understanding of how these preand postsynaptic purinoceptors are activated by endogenous purines in brain slices and in the brain in vivo. Whereas suppression of glutamatergic transmission by ATP of astrocyteorigin occurs through the activation of presynaptic $\mathrm{P} 2 \mathrm{Y}_{1}$ receptors in cultured hippocampal neuron-glia co-cultures, it occurs through activation of presynaptic $A_{1}$ receptors in acute slices, due to strong hydrolyzing activity around the synapses in the slices, as evidenced by its inhibition using ecto-5'-nucleotidase inhibitors [63]. Such effects of ATP of astrocyte-origin on $A_{1}$ receptors are confirmed by the use of gliotoxins [63], by perfusion of gap junction-linked astrocyte syncytium with a $\mathrm{Ca}^{2+}$ chelator, BAPTA, combined with evaluation of heterosynaptic depression in the hippocampus [108], and by using mice carrying astrocyte-specific expression of a dominant negative form of synaptobrevin-2 [66]. This mouse also shows abnormalities in sleep homeostasis and cognitive deficits associated with sleep loss, suggesting adenosine derived from ATP of astrocyte origin plays a role in sleep maintenance [109].

The mechanism of ATP release from astrocytes is a topic of debate. The following four mechanisms have been proposed, each with convincing demonstration: 1) through vesicular exocytosis [66, 110], 2) through hemi-channels, which are connexin or pannexin channels expressed on the membrane surface without their counterpart to form cell-tocell gap junctions $[111,112], 3)$ through $\mathrm{P}_{2} \mathrm{X}_{7}$ receptor channels that have large conductance pores [113], and 4) through large-conductance anion channels, the molecular identity of which remains unidentified [114, 115]. At this moment, it seems that pathways for ATP release from astro- 
cytes may depend on the type of stimulus, region, and subcellular structures.

Nevertheless, direct demonstrations of modulation of synaptic transmission by ATP or adenosine of astrocyte origin in native brain tissue are currently scarce. Yamazaki et al. demonstrated, in the hippocampal slice, that experimental depolarization of a single astrocyte suppresses excitatory transmission recorded in adjacent neurons in a manner sensitive to ecto-5'-nucleotidase inhibitor and adenosine $A_{1}$ antagonist[116], suggesting activation of astrocytes can indeed modulate synaptic transmission through the release of ATP and subsequent conversion to adenosine. In addition, they also demonstrated a continuous firing of the neuron, which in turn modifies the membrane properties of astrocytes, arguing strongly for mutual astrocyte-neuron interaction. Open questions for understanding the physiological and pathophysiological significance of the purinergic neuron-astrocyte interaction include, in which situations and through which mechanisms do astrocytes release ATP to synapses and how is the quantitative balance between ATP, ADP and adenosine determined by ecto-5'-nucleotidase to determine the resulting synaptic responses?

\section{CONCLUSIONS}

Astrocytes and microglia express many types of purinoceptors and the stimulation of these receptors cause the release of gliotransmitters (ATP, glutamate, cytokines etc.) affecting synaptic transmission. In this article, $\mathrm{P}_{2} \mathrm{X}_{4} \mathrm{R}$ and $\mathrm{P} 2 \mathrm{Y}_{12} \mathrm{R}$ systems of microglia for modulation of the synaptic transmission between dorsal root ganglion neurons and dorsal horn neurons are mainly described. $\mathrm{P} 2 \mathrm{X}_{7} \mathrm{R}$ of microglia is also tightly correlated with the release of cytokines that affect synaptic transmission in several part of nervous system though we did not mentioned the role of this receptors in this paper. Astrocytic purinergic system in synaptic transmission was also mentioned mainly in the case of hippocampus. The modulation of synaptic transmission by glial purinergic system is a novel insight of the regulation of brain and nerve function, especially abnormal and disease of brain functions. Therefore, glial purinergic system might be a new target for developing medicines.

\section{REFERENCES}

[1] Burnstock G. Purinergic nerves. Pharmacol Rev 1972; 24: 509-81.

[2] Burnstock G, Knight GE. Cellular distribution and functions of P2 receptor subtypes in different systems. Int Rev Cytol 2004; 240: 31-304.

[3] Ralevic V, Burnstock G. Receptors for purines and pyrimidines. Pharmacol Rev 1998; 50: 413-92.

[4] Khakh BS, Burnstock G, Kennedy C, et al. International union of pharmacology. XXIV. Current status of the nomenclature and properties of P2X receptors and their subunits. Pharmacol Rev 2001; 53: 107-18

[5] Abbracchio MP, Burnstock G, Boeynaems JM, et al. International Union of Pharmacology LVIII: update on the P2Y G proteincoupled nucleotide receptors: from molecular mechanisms and pathophysiology to therapy. Pharmacol Rev 2006; 58: 281-341.

[6] Burnstock G. Purinergic signalling and disorders of the central nervous system. Nat Rev Drug Discov 2008; 7: 575-90.

[7] Kreutzberg GW. Microglia: a sensor for pathological events in the CNS. Trends Neurosci 1996; 19: 312-8.

[8] Stoll G, Jander S. The role of microglia and macrophages in the pathophysiology of the CNS. Prog Neurobiol 1999; 58: 233-47.

[9] Inoue K. The function of microglia through purinergic receptors: Neuropathic pain and cytokine release. Pharmacol Ther 2006; 109: 210-26.
[10] Davalos D, Grutzendler J, Yang G, et al. ATP mediates rapid microglial response to local brain injury in vivo. Nat Neurosci 2005; 8: 752-8.

[11] Nimmerjahn A, Kirchhoff F, Helmchen F. Resting microglial cells are highly dynamic surveillants of brain parenchyma in vivo. Science 2005; 308: 1314-8.

[12] Haynes SE, Hollopeter G, Yang G, et al. The P2Y(12) receptor regulates microglial activation by extracellular nucleotides. Nat Neurosci 2006; 9: 1512-9.

[13] Tsuda M, Inoue K, Salter MW. Neuropathic pain and spinal microglia: a big problem from molecules in "small" glia. Trends Neurosci 2005; 28: 101-7.

[14] Hanisch UK, Kettenmann H. Microglia: active sensor and versatile effector cells in the normal and pathologic brain. Nat Neurosci 2007; 10: 1387-94.

[15] Honda S, Sasaki Y, Ohsawa K, et al. Extracellular ATP or ADP induce chemotaxis of cultured microglia through Gi/o-coupled P2Y receptors. J Neurosci 2001; 21: 1975-82.

[16] Eriksson NP, Persson JK, Svensson M, et al. A quantitative analysis of the microglial cell reaction in central primary sensory projection territories following peripheral nerve injury in the adult rat. Exp Brain Res 1993; 96: 19-27.

[17] Coyle DE. Partial peripheral nerve injury leads to activation of astroglia and microglia which parallels the development of allodynic behavior. Glia 1998; 23: 75-83.

[18] Colburn RW, Rickman AJ, DeLeo JA. The effect of site and type of nerve injury on spinal glial activation and neuropathic pain behavior. Exp Neurol 1999; 157: 289-304.

[19] Stuesse SL, Cruce WL, Lovell JA, et al. Microglial proliferation in the spinal cord of aged rats with a sciatic nerve injury. Neurosci Lett 2000; 287: 121-4.

[20] Zhang J, De Koninck Y. Spatial and temporal relationship between monocyte chemoattractant protein-1 expression and spinal glial activation following peripheral nerve injury. J Neurochem 2006; 97: 772-83.

[21] Beggs S, Salter MW. Stereological and somatotopic analysis of the spinal microglial response to peripheral nerve injury. Brain Behav Immun 2007; 21: 624-33.

[22] Tsuda M, Shigemoto-Mogami Y, Koizumi S, et al. $\mathrm{P} 2 \mathrm{X}_{4}$ receptors induced in spinal microglia gate tactile allodynia after nerve injury. Nature 2003; 424: 778-83.

[23] Zhang RX, Liu B, Wang L, et al. Spinal glial activation in a new rat model of bone cancer pain produced by prostate cancer cell inoculation of the tibia. Pain 2005; 118: 125-36.

[24] Peters CM, Jimenez-Andrade JM, Jonas BM, et al. Intravenous paclitaxel administration in the rat induces a peripheral sensory neuropathy characterized by macrophage infiltration and injury to sensory neurons and their supporting cells. Exp Neurol 2007; 203: 42-54.

[25] Tsuda M, Ueno H, Kataoka A, et al. Activation of dorsal horn microglia contributes to diabetes-induced tactile allodynia via extracellular signal-regulated protein kinase signaling. Glia 2008; 56: 378-86.

[26] Clark AK, Yip PK, Grist J, et al. Inhibition of spinal microglial cathepsin $\mathrm{S}$ for the reversal of neuropathic pain. Proc Natl Acad Sci USA 2007; 104: 10655-60.

[27] Zhang J, Shi XQ, Echeverry S, et al. Expression of CCR2 in both resident and bone marrow-derived microglia plays a critical role in neuropathic pain. J Neurosci 2007; 27: 12396-406.

[28] Thacker MA, Clark AK, Bishop T, et al. CCL2 is a key mediator of microglia activation in neuropathic pain states. Eur J Pain 2009; 13: 263-72.

[29] Liu L, Tornqvist E, Mattsson P, et al. Complement and clusterin in the spinal cord dorsal horn and gracile nucleus following sciatic nerve injury in the adult rat. Neuroscience 1995; 68: 167-79.

[30] Tanaka T, Minami M, Nakagawa T, et al. Enhanced production of monocyte chemoattractant protein-1 in the dorsal root ganglia in a rat model of neuropathic pain: possible involvement in the development of neuropathic pain. Neurosci Res 2004; 48: 463-9.

[31] White FA, Sun J, Waters SM, et al. Excitatory monocyte chemoattractant protein-1 signaling is up-regulated in sensory neurons after chronic compression of the dorsal root ganglion. Proc Natl Acad Sci USA 2005; 102: 14092-7.

[32] Tanga FY, Nutile-McMenemy N, DeLeo JA. The CNS role of Toll-like receptor 4 in innate neuroimmunity and painful neuropathy. Proc Natl Acad Sci USA 2005; 102: 5856-61. 
[33] Kim D, Kim MA, Cho IH, et al. A critical role of toll-like receptor 2 in nerve injury-induced spinal cord glial cell activation and pain hypersensitivity. J Biol Chem 2007; 282: 14975-83.

[34] Tsuda M, Masuda T, Kitano J, et al. IFN-gamma receptor signaling mediates spinal microglia activation driving neuropathic pain. Proc Natl Acad Sci USA 2009; 106: 8032-7.

[35] Ulmann L, Hatcher JP, Hughes JP, et al. Up-regulation of $\mathrm{P} 2 \mathrm{X}_{4}$ receptors in spinal microglia after peripheral nerve injury mediates BDNF release and neuropathic pain. J Neurosci 2008; 28: 11263-8.

[36] Tsuda M, Kuboyama K, Inoue T, et al. Behavioral phenotypes of mice lacking purinergic $\mathrm{P} 2 \mathrm{X}_{4}$ receptors in acute and chronic pain assays. Mol Pain 2009; 5: 28.

[37] Woolf CJ, Salter MW. Neuronal plasticity: increasing the gain in pain. Science 2000; 288: 1765-9.

[38] Scholz J, Woolf CJ. Can we conquer pain? Nat Neurosci 2002; 5 Suppl: 1062-7.

[39] Coull JA, Beggs S, Boudreau D, et al. BDNF from microglia causes the shift in neuronal anion gradient underlying neuropathic pain. Nature 2005; 438: 1017-21.

[40] Coull JA, Boudreau D, Bachand K, et al. Trans-synaptic shift in anion gradient in spinal lamina I neurons as a mechanism of neuropathic pain. Nature 2003; 424: 938-42.

[41] Trang T, Beggs S, Wan X, et al. $\mathrm{P} 2 \mathrm{X}_{4}$-receptor-mediated synthesis and release of brain-derived neurotrophic factor in microglia is dependent on calcium and p38-mitogen-activated protein kinase activation. J Neurosci 2009; 29: 3518-28.

[42] Jin SX, Zhuang ZY, Woolf CJ, et al. p38 mitogen-activated protein kinase is activated after a spinal nerve ligation in spinal cord microglia and dorsal root ganglion neurons and contributes to the generation of neuropathic pain. J Neurosci 2003; 23: 4017-22.

[43] Tsuda M, Mizokoshi A, Shigemoto-Mogami Y, et al. Activation of p38 mitogen-activated protein kinase in spinal hyperactive microglia contributes to pain hypersensitivity following peripheral nerve injury. Glia 2004; 45: 89-95.

[44] Inoue K. Microglial activation by purines and pyrimidines. Glia 2002; 40: 156-63.

[45] Viviani B, Bartesaghi S, Gardoni F, et al. Interleukin-1beta enhances NMDA receptor-mediated intracellular calcium increase through activation of the Src family of kinases. J Neurosci 2003; 23: 8692-700.

[46] Vikman KS, Hill RH, Backstrom E, et al. Interferon-gamma induces characteristics of central sensitization in spinal dorsal horn neurons in vitro. Pain 2003; 106: 241-51.

[47] Nasu-Tada K, Koizumi S, Tsuda M, et al. Possible involvement of increase in spinal fibronectin following peripheral nerve injury in upregulation of microglial P2X(4), a key molecule for mechanical allodynia. Glia 2006; 53: 769-75.

[48] Tsuda M, Toyomitsu E, Kometani M, et al. Mechanisms underlying fibronectin-induced upregulation of P2XR expression in microglia: distinct roles of PI3K-Akt and MEK-ERK signaling pathways. J Cell Mol Med 2009; 13: 3251-59.

[49] Tsuda M, Tozaki-Saitoh H, Masuda T, et al. Lyn tyrosine kinase is required for $\mathrm{P} 2 \mathrm{X}(4)$ receptor upregulation and neuropathic pain after peripheral nerve injury. Glia 2008; 56: 50-8.

[50] Guo LH, Guo KT, Wendel HP, et al. Combinations of TLR and NOD2 ligands stimulate rat microglial P2X4R expression. Biochem Biophys Res Commun 2006; 349: 1156-62.

[51] Enkvist MO, Holopainen I, Akerman KE. Alpha-receptor and cholinergic receptor-linked changes in cytosolic $\mathrm{Ca}^{2+}$ and membrane potential in primary rat astrocytes. Brain Res 1989; 500: 4654.

[52] Cornell-Bell AH, Finkbeiner SM, Cooper MS, et al. Glutamate induces calcium waves in cultured astrocytes: long-range glial signaling. Science 1990; 247: 470-3.

[53] Haydon PG. GLIA: listening and talking to the synapse. Nat Rev Neurosci 2001; 2: 185-93.

[54] Dani JW, Chernjavsky A, Smith SJ. Neuronal activity triggers calcium waves in hippocampal astrocyte networks. Neuron 1992; 8: 429-40.

[55] Boitano S, Dirksen ER, Sanderson MJ. Intercellular propagation of calcium waves mediated by inositol trisphosphate. Science 1992; 258: 292-5.

[56] Sneyd J, Charles AC, Sanderson MJ. A model for the propagation of intercellular calcium waves. Am J Physiol 1994; 266: C293-302.
[57] Sneyd J, Wetton BT, Charles AC, et al. Intercellular calcium waves mediated by diffusion of inositol trisphosphate: a two-dimensional model. Am J Physiol 1995; 268: C1537-45.

[58] Guthrie PB, Knappenberger J, Segal M, et al. ATP released from astrocytes mediates glial calcium waves. J Neurosci 1999; 19: 5208.

[59] Cotrina ML, Lin JH, Lopez-Garcia JC, et al. ATP-mediated glia signaling. J Neurosci 2000; 20: 2835-44.

[60] Newman EA. Propagation of intercellular calcium waves in retinal astrocytes and Muller cells. J Neurosci 2001; 21: 2215-23.

[61] Fam SR, Gallagher CJ, Salter MW. P2Y(1) purinoceptor-mediated $\mathrm{Ca}(2+)$ signaling and $\mathrm{Ca}(2+)$ wave propagation in dorsal spinal cord astrocytes. J Neurosci 2000; 20: 2800-8.

[62] Koizumi S, Fujishita K, Tsuda M, et al. Dynamic inhibition of excitatory synaptic transmission by astrocyte-derived ATP in hippocampal cultures. Proc Natl Acad Sci USA 2003; 100: 11023-8.

[63] Zhang JM, Wang HK, Ye CQ, et al. ATP released by astrocytes mediates glutamatergic activity-dependent heterosynaptic suppression. Neuron 2003; 40: 971-82.

[64] Ogura A, Iijima T, Amano T, et al. Optical monitoring of excitatory synaptic activity between cultured hippocampal neurons by a multi-site $\mathrm{Ca}^{2+}$ fluorometry. Neurosci Lett 1987; 78: 69-74.

[65] Koizumi S, Inoue K. Inhibition by ATP of calcium oscillations in rat cultured hippocampal neurones. Br J Pharmacol 1997; 122: 518.

[66] Pascual O, Casper KB, Kubera C, et al. Astrocytic purinergic signaling coordinates synaptic networks. Science 2005; 310: 113-6.

[67] Newman EA. Calcium signaling in retinal glial cells and its effect on neuronal activity. Prog Brain Res 2001; 132: 241-54.

[68] Newman EA. Glial cell inhibition of neurons by release of ATP. J Neurosci 2003; 23: 1659-66.

[69] Newman EA. Calcium increases in retinal glial cells evoked by light-induced neuronal activity. J Neurosci 2005; 25: 5502-10.

[70] Edwards FA, Gibb AJ, Colquhoun D. ATP receptor-mediated synaptic currents in the central nervous system. Nature 1992; 359: 144-7.

[71] Pankratov Y, Lalo U, Krishtal O, et al. P2X receptor-mediated excitatory synaptic currents in somatosensory cortex. Mol Cell Neurosci 2003; 24: 842-9.

[72] Pankratov Y, Lalo U, Krishtal O, et al. Ionotropic P2X purinoreceptors mediate synaptic transmission in rat pyramidal neurones of layer II/III of somato-sensory cortex. J Physiol 2002; 542: 529-36.

[73] Masaki E, Kawamura M, Kato F. Reduction by sevoflurane of adenosine 5'-triphosphate-activated inward current of locus coeruleus neurons in pontine slices of rats. Brain Res 2001; 921: 22632.

[74] Pankratov Y, Castro E, Miras-Portugal MT, et al. A purinergic component of the excitatory postsynaptic current mediated by $\mathrm{P} 2 \mathrm{X}$ receptors in the CA1 neurons of the rat hippocampus. Eur J Neurosci 1998; 10: 3898-902.

[75] Jo YH, Role LW. Cholinergic modulation of purinergic and GABAergic co-transmission at in vitro hypothalamic synapses. J Neurophysiol 2002; 88: 2501-8.

[76] Bardoni R, Goldstein PA, Lee CJ, et al. ATP P2X receptors mediate fast synaptic transmission in the dorsal horn of the rat spinal cord. J Neurosci 1997; 17: 5297-304.

[77] Mori M, Heuss C, Gahwiler $\mathrm{BH}$, et al. Fast synaptic transmission mediated by $\mathrm{P} 2 \mathrm{X}$ receptors in $\mathrm{CA} 3$ pyramidal cells of rat hippocampal slice cultures. J Physiol 2001; 535: 115-23.

[78] Nieber K, Poelchen W, Illes P. Role of ATP in fast excitatory synaptic potentials in locus coeruleus neurones of the rat. Br J Pharmacol 1997; 122: 423-30.

[79] Benham CD. ATP joins the fast lane. Nature 1992; 359: 103-4.

[80] Gordon GR, Baimoukhametova DV, Hewitt SA, et al. Norepinephrine triggers release of glial ATP to increase postsynaptic efficacy. Nat Neurosci 2005; 8: 1078-86.

[81] Robertson SJ, Edwards FA. ATP, synaptically released in the brain, is not a cotransmitter with glutamate. Neurosci Abs 1996; 22: 617.1 .

[82] Khakh BS, Henderson G. ATP receptor-mediated enhancement of fast excitatory neurotransmitter release in the brain. Mol Pharmacol 1998; 54: 372-8.

[83] Khakh BS, Henderson G. Modulation of fast synaptic transmission by presynaptic ligand-gated cation channels. J Auton Ner Syst 2000; 81: 110-21. 
[84] Rhee JS, Wang ZM, Nebekura J, et al. ATP facilitates spontaneous glycinergic IPSC frequency at dissociated rat dorsal horn interneuron synapses. J Physiol 2000; 524: 471-83.

[85] Kato F, Shigetomi E. Distinct modulation of evoked and spontaneous EPSCs by purinoceptors in the nucleus tractus solitarii of the rat. J Physiol 2001; 530: 469-86.

[86] Khakh BS, Gittermann D, Cockayne DA, et al. ATP modulation of excitatory synapses onto interneurons. J Neurosci 2003; 23: 742637.

[87] Donato R, Rodrigues RJ, Takahashi M, et al. GABA release by basket cells onto Purkinje cells, in rat cerebellar slices, is directly controlled by presynaptic purinergic receptors, modulating $\mathrm{Ca}^{2+}$ influx. Cell Calcium 2008; 44: 521-32.

[88] Shigetomi E, Kato F. Action potential-independent release of glutamate by $\mathrm{Ca}^{2+}$ entry through presynaptic $\mathrm{P} 2 \mathrm{X}$ receptors elicits postsynaptic firing in the brainstem autonomic network. J Neurosci 2004; 24: 3125-35.

[89] Zimmermann H. Extracellular metabolism of ATP and other nucleotides. Naunyn-Schmiedberg's Arch Pharmacol 2000; 362: 299309.

[90] Dunwiddie TV, Diao L, Proctor WR. Adenine nucleotides undergo rapid, quantitative conversion to adenosine in the extracellular space in rat hippocampus. J Neurosci 1997; 17: 7673-82.

[91] Masino SA, Diao L, Illes P, et al. Modulation of Hippocampal Glutamatergic Transmission by ATP is Dependent on Adenosine A1 Receptors. J Pharmacol Exp Ther 2002; 303: 356-63.

[92] Kawamura M, Gachet C, Inoue K, et al. Direct excitation of inhibitory interneurons by extracellular ATP mediated by $\mathrm{P}_{2} \mathrm{Y}_{1}$ receptors in the hippocampal slice. J Neurosci 2004; 24: 10835-45.

[93] Zamponi GW. Determinants of G protein inhibition of presynaptic calcium channels. Cell Biochem Biophys 2001; 34: 79-94.

[94] Fredholm BB, Dunwiddie TV. How does adenosine inhibit transmitter release? Trends Pharmacol Sci 1988; 9: 130-5.

[95] Kato F, Kawamura M, Shigetomi E, et al. ATP- and adenosinemediated signaling in the central nervous system: synaptic purinoceptors: the stage for ATP to play its "dual-role". J Pharmacol Sci 2004; 94: 107-11.

[96] Jabs R, Matthias K, Grote A, et al. Lack of P2X receptor mediated currents in astrocytes and GluR type glial cells of the hippocampal CA1 region. Glia 2007; 55: 1648-55.

[97] Safiulina VF, Afzalov R, Khiroug L, et al. Reactive oxygen species mediate the potentiating effects of ATP on GABAergic synaptic transmission in the immature hippocampus. J Biol Chem 2006; 281: 23464-70.

[98] Quiroz C, Lujan R, Uchigashima M, et al. Key modulatory role of presynaptic adenosine $\mathrm{A}_{2 \mathrm{~A}}$ receptors in cortical neurotransmission to the striatal direct pathway. ScientificWorldJournal 2009; 9: 1321-44.

[99] Ferre S, Ciruela F, Quiroz C, et al. Adenosine receptor heteromers and their integrative role in striatal function. ScientificWorldJournal 2007; 7: 74-85.
[100] Ferre S, Ciruela F, Borycz J, et al. Adenosine $\mathrm{A}_{1}-\mathrm{A}_{2 \mathrm{~A}}$ receptor heteromers: new targets for caffeine in the brain. Front Biosci 2008; 13: 2391-9.

[101] Lopes LV, Cunha RA, Kull B, et al. Adenosine A(2A) receptor facilitation of hippocampal synaptic transmission is dependent on tonic A(1) receptor inhibition. Neuroscience 2002; 112: 319-29.

[102] Zahniser NR, Simosky JK, Mayfield RD, et al. Functional uncoupling of adenosine $\mathrm{A}_{2 \mathrm{~A}}$ receptors and reduced response to caffeine in mice lacking dopamine $\mathrm{D}_{2}$ receptors. J Neurosci 2000; 20: 594957.

[103] Boison D. Adenosine and epilepsy: from therapeutic rationale to new therapeutic strategies. Neuroscientist 2005; 11: 25-36.

[104] Stenberg D, Litonius E, Halldner L, et al. Sleep and its homeostatic regulation in mice lacking the adenosine $\mathrm{A}_{1}$ receptor. J Sleep Res 2003; 12: 283-90.

[105] Rebola N, Lujan R, Cunha RA, et al. Adenosine A2A receptors are essential for long-term potentiation of NMDA-EPSCs at hippocampal mossy fiber synapses. Neuron 2008; 57: 121-34.

[106] Rex CS, Kramar EA, Colgin LL, et al. Long-term potentiation is impaired in middle-aged rats: regional specificity and reversal by adenosine receptor antagonists. J Neurosci 2005; 25: 5956-66.

[107] Queiroz G, Meyer DK, Meyer A, et al. A study of the mechanism of the release of ATP from rat cortical astroglial cells evoked by activation of glutamate receptors. Neuroscience 1999; 91: 1171-81.

[108] Serrano A, Haddjeri N, Lacaille JC, et al. GABAergic network activation of glial cells underlies hippocampal heterosynaptic depression. J Neurosci 2006; 26: 5370-82.

[109] Halassa MM, Florian C, Fellin T, et al. Astrocytic modulation of sleep homeostasis and cognitive consequences of sleep loss. Neuron 2009; 61: 213-9.

[110] Sawada K, Echigo N, Juge N, et al. Identification of a vesicular nucleotide transporter. Proc Natl Acad Sci USA 2008; 105: 5683-6.

[111] Kang J, Kang N, Lovatt D, et al. Connexin 43 hemichannels are permeable to ATP. J Neurosci 2008; 28: 4702-11.

[112] Iglesias R, Dahl G, Qiu F, et al. Pannexin 1: the molecular substrate of astrocyte "hemichannels". J Neurosci 2009; 29: 7092-7.

[113] Hamilton N, Vayro S, Kirchhoff F, et al. Mechanisms of ATP- and glutamate-mediated calcium signaling in white matter astrocytes. Glia 2008; 56: 734-49.

[114] Liu HT, Toychiev AH, Takahashi N, et al. Maxi-anion channel as a candidate pathway for osmosensitive ATP release from mouse astrocytes in primary culture. Cell Res 2008; 18: 558-65.

[115] Liu HT, Sabirov RZ, Okada Y. Oxygen-glucose deprivation in duces ATP release via maxi-anion channels in astrocytes. Purinergic Signal 2008; 4: 147-54.

[116] Yamazaki Y, Hozumi Y, Kaneko K, et al. Direct evidence for mutual interactions between perineuronal astrocytes and interneurons in the CA1 region of the rat hippocampus. Neuroscience 2005; 134: 791-802.

(C) Inoue et al.; Licensee Bentham Open.

This is an open access article licensed under the terms of the Creative Commons Attribution Non-Commercial License (http://creativecommons.org/licenses/by-nc/3.0/) which permits unrestricted, non-commercial use, distribution and reproduction in any medium, provided the work is properly cited. 